\title{
Application of Mobile Intelligent Inspection System in Substation Equipment Management
}

\author{
Danli Long \\ Guilin Power Supply Bureau (Guangxi Power Grid Corporation), Guilin, China \\ Email: longdanli@163.com
}

How to cite this paper: Long, D.L. (2017) Application of Mobile Intelligent Inspection System in Substation Equipment Management. Energy and Power Engineering, 9, 408-413.

https://doi.org/10.4236/epe.2017.94B046

Received: February 25, 2017

Accepted: March 30, 2017

Published: April 6, 2017

\begin{abstract}
Intelligent inspection is more and more widely applied in all walks of life. This paper introduces the application of the intelligent inspection system in substation equipment management based on mobile phone terminal. It can make the power supply enterprise have more effective means to ensure the safe operation of equipment, improve equipment management level, and improve the economic benefits of power supply.
\end{abstract}

\section{Keywords}

Mobile Intelligent Inspection System, Substation Operating, Device Management

\section{Introduction}

The safe and efficient operation of substation equipment are directly related with the security of power systems, while the inspection is an essential measure to ensure the safe operation of the equipment.

With the rapid development of large data, networking, mobile Internet and other information technology, the smart mobile devices represented by intelligent mobile phone are popularized rapidly [1]. Since it includes a multitude of standard features and benefits, such as small size, light weight, easy to carry, both camera and video, audio and text transmission, GPS positioning, communication and so on, the intelligent mobile phone is becoming more and more widely used in power system inspection work. A mobile-based information system can not only reduce writing errors caused by human negligence, but also reduce workload and elevate the quality of work [2].

A privacy protection system for equipment inspection is proposed in [3], including an improved algorithm based on k-anonymous algorithm, which can make privacy information anonymous efficiently, especially in fields with few 
workers. In order to solve the remote real-time monitoring problems of distribution, [4] designs a real-time monitoring management system of the distribution transformer based on wireless private network. The communications channel takes advantage of the advanced APN technology to set up wireless private network which ensures fast, reliable, safety running of the entire system. In [5], technologies including the mobile GIS, wireless network, mobile positioning and data encryption are studied and a patrol inspection mobile navigation and positioning system in geographic information system is designed, which is implemented in Bai Miao substation belonging to Tianjin electric power company. And in [6], an intelligent equipment with high frequency RFID read-write functions is used as the mobile inspection terminal for a hydropower plant inspection management system.

\section{Features of the Mobile Intelligent Inspection Management System}

\subsection{Main Problems Existing in Traditional Inspection Methods}

The main problems existing in traditional inspection methods are as follows:

- The situation of staff in place is unable to query. These phenomena such as leak detection and inadequate inspection still exist.

- Handwritten inspection data need be recorded for two times. This is time-consuming and laborious. And the inspection results may not be effectively accumulated, studied and shared.

- Traditional inspection methods could not get some data of inspection, such as live pictures, videos and location information. Inspection information feedback is not timely, which lead to the orientation and guidance of abnormal inspection results are not immediately.

- It is difficult for managers to know the real-time situation of site inspection staff timely, accurately and comprehensively [7].

- It is difficult to trace and check the inspection history.

\subsection{Features of the Mobile Intelligent Inspection Management System}

With the construction of the power grid, the substation equipment is increasing. It is urgent to establish a set of effective inspection management system to improve the efficiency of substation equipment inspection, and then ensure the safe operation of power grid.

In this paper, the mobile intelligent inspection system is a new type of substation inspection management system which combines computer technology, mobile Internet technology, data communication technology, GPS positioning technology and reliability theory. It can effectively prevent the traditional substation equipment inspection defects, such as the inspection quality is not high, false inspection, inspection route not consistent with the regulations, detection of abnormal surface information is not timely, feedback delay, data is incomplete and inaccurate, data query and management are relatively difficult. 
The main features of the mobile intelligent inspection management system include:

- The system can effectively get site inspection staff's position and playback inspection track, to avoid issues like omission or false inspection.

- The intelligent inspection terminal of mobile phone can record the data and information of the mobile phone directly in digital form, so as to improve the work efficiency.

- Mobile intelligent terminal can detect the scene in a timely manner, to take pictures, audio, video, and can submit alarm and location information in real time, in order to quickly locate site inspection staffs, analysis and give a solution.

- Site inspection staff can improve the statistical analysis report, the implementation of statistical inspection plan, statistics the number of abnormal conditions and the time, and classified analysis, to further optimize the management process.

- The system can integrate with a background monitoring management system to improve the efficiency of the entire power grid management.

\section{Mobile Intelligent Inspection Management System}

The mobile intelligent inspection system is composed of inspection monitoring management center, communication network and mobile intelligent terminal (see Figure 1).

\subsection{Inspection Monitoring Management Center}

Inspection management center is composed of hardware and software. The hardware includes server, monitor, printer, UPS, main station communication network equipment, large screen display system and so on. The software includes real-time database software, database management software, web publishing software, data acquisition software and so on.

\subsection{Mobile Intelligent Terminal}

By the smart phone and inspection APP software, inspection APP support

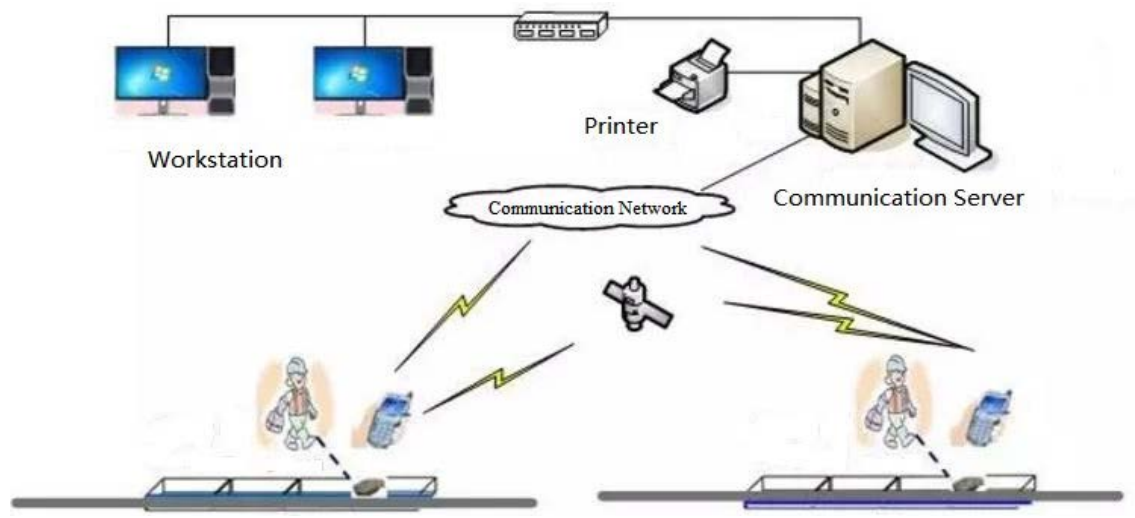

Figure 1. Constitution of the mobile intelligent inspection system. 
Android and IOS devices. Inspection officers carry a smart phone equipped with APP inspection can facilitate the inspection operations by the use of GPRS/4G network, GPS positioning function.

Mobile phone intelligent inspection terminal, as the main equipment of the inspection system, collects inspection information on site and realizes data synchronization with a background server of monitoring center, to achieve the effective integration of inspection and inspection terminal monitoring center platform.

Ordinary smart phones can be installed intelligent inspection APP. The intelligent inspection APP support Android and iOS devices, so no extra configuration hardware equipment are needed. The mobile terminal automatically receives the inspection task from inspection management center, interacts with the server, and checks the standard. Mobile home page can view the task completed, abnormal statistics and other information. Mobile terminal supports reading two-dimensional code and bar code (see Figure 2 and Figure 3), automatically receives the satellite positioning signal, and sends the current location to the server in real time.

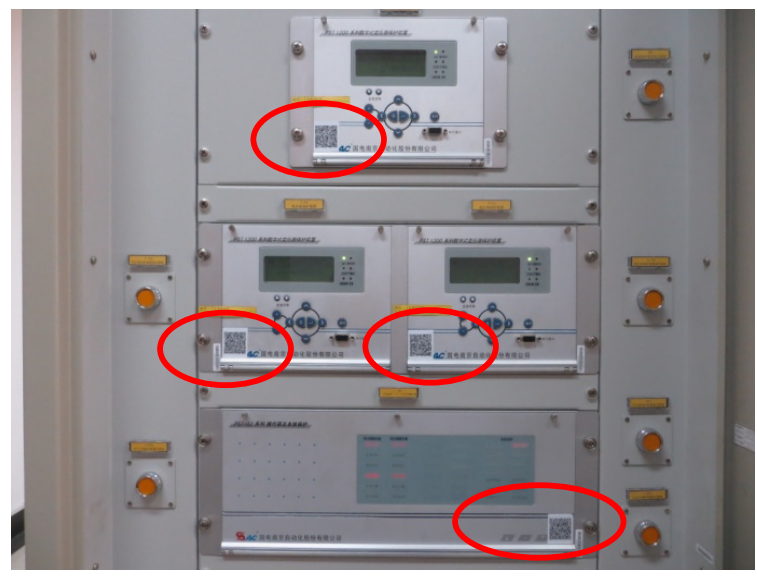

Figure 2. Two-dimensional codes pasted on substation equipments.

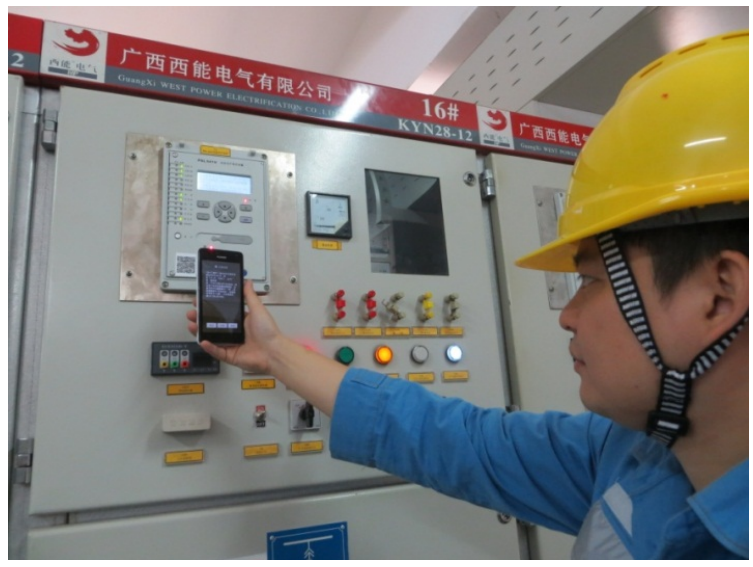

Figure 3. Reading two-dimensional code by mobile terminal. 
Inspection records can be described in words, pictures, video and other digital data directly uploaded to the server. As shown in Figure 4, the data is easy storage, statistics, analysis. And other managers can be more intuitive understanding of the situation of the inspection site.

Inspection staff can view their current location information in real time and check the location of inspection equipment to improve work efficiency. They can easily view the operation and maintenance staff contact information through an integrated enterprise address book (see Figure 5).

\subsection{Communication Network}

Through the GPS positioning network and wireless communication GPRS/4G network, the real-time interaction between the inspection management center and the mobile intelligent terminal is realized. The information includes the equipment manufacturer, ratings, last inspection time and real-time operating data [8]. We upload a test data by different smart phone. Smartphones can upload successfully. Table 1 displays the test results.

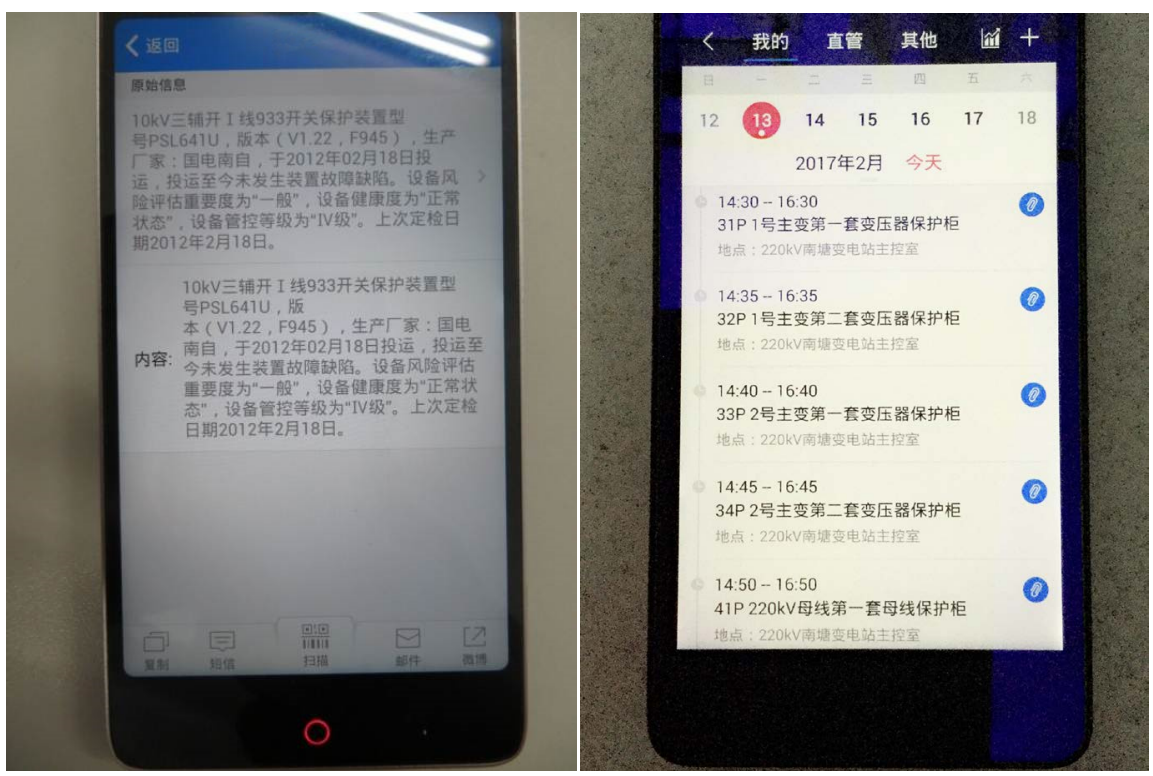

Figure 4. Mobile intelligent inspection APP data interfaces.

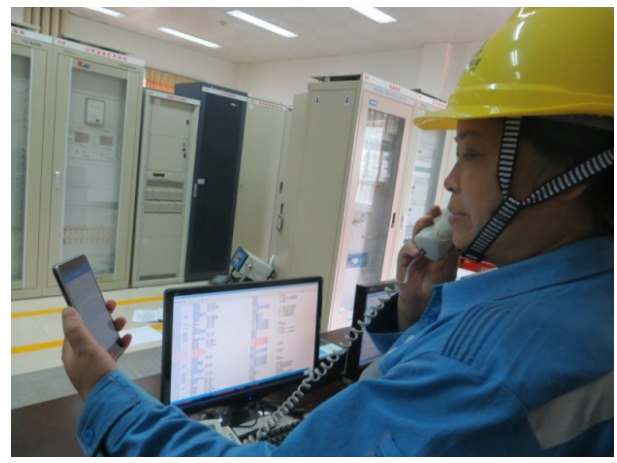

Figure 5. Inspection staff can easily view the operation and maintenance staff contact information. 
Table 1. Test results of data upload time.

\begin{tabular}{cccc}
\hline Smartphone models & Total upload times & Total time $(\mathrm{s})$ & Average time $(\mathrm{s})$ \\
\hline Xiaomi Note 4X & 100 & 186 & 1.86 \\
iPhone 7 Plus & 100 & 139 & 1.39 \\
vivo X9 & 100 & 163 & 1.63 \\
honor 6X & 100 & 147 & 1.47 \\
\hline
\end{tabular}

\section{Conclusion}

This paper presents a mobile phone intelligent inspection system. It is a powerful system which can well solve the problems in the operation of substation equipment inspection. The hardware platform is stable and the investment of management is less than traditional inspection methods. It benefits the improvement of substation inspection standard and scientific level, and the safe operation of power grid, so as to enhance the economic benefits of power supply.

\section{References}

[1] Liu, G., Zhu, W., Chen, J. and Zhang, Y. (2005) Characteristics, Application Scenarios and Analysis Platform of Smart Grid Big Data. Southern Power System Technology, 10, 102-110.

[2] Tang,S. Y., Chen, C.L. and Hung, L.P. (2015) Development of Mobile-Based Intelligent Surgery Information System. 201511 th International Conference on Heterogeneous Networking for Quality, Reliability, Security and Robustness (QSHINE), Taipei, 23 November 2015, 398-403. https://doi.org/10.4108/eai.19-8-2015.2261093

[3] Xu, C.F., Tao, F.B., Gong, Y.F., Cao, J. and Wang, X.W. (2015) A Privacy Protection System for Equipment Inspection Based on Mobile Terminals. 2015 4th International Conference on Computer Science and Network Technology (ICCSNT), Harbin, 19-20 December 2015.

[4] Zheng, Y., Jiao, P. and Zhang, Z. (2009) Real-Time Monitoring Management System of the Distribution Transformer Based on Wireless Private Network. Power System Protection and Control, 37, 96-98.

[5] He, J., Wang, Y., Dong. Y., Yin, B. and Wang, J. (2014) The Patrol Inspection Mobile Navigation and Positioning System in Geographic Information System. Electric Power ICT, 12, 7-11.

[6] Huang, L., Zhu, W., Li Y., Guo, J. and Zhang, F. (2016) Hydropower Plant Inspection Management System Based on RFID. Water Resources and Power, 34, 166-169.

[7] Liu, D. and Peng, L. (2005) Application of Mobile Location Technology in Electric Power Inspection Management. Electric Power, 38, 83-86.

[8] Xu, C.F., Tao, F.B., Gong, Y.F., Cao, J. and Wang, X.W. (2016) Substation RealTime Data Transmission and Early Warnings Based on 4G Private Network of Power System. 2016 China International Conference on Electricity Distribution (CICED), Xi'an, 10-13 September 2016. https://doi.org/10.1109/ciced.2016.7576270 
Submit or recommend next manuscript to SCIRP and we will provide best service for you:

Accepting pre-submission inquiries through Email, Facebook, LinkedIn, Twitter, etc. A wide selection of journals (inclusive of 9 subjects, more than 200 journals)

Providing 24-hour high-quality service

User-friendly online submission system

Fair and swift peer-review system

Efficient typesetting and proofreading procedure

Display of the result of downloads and visits, as well as the number of cited articles Maximum dissemination of your research work

Submit your manuscript at: http://papersubmission.scirp.org/

Or contact epe@scirp.org 